\title{
Autosomal recessive limb-girdle muscular dystrophy type 2A
}

INSERM

\section{Source}

INSERM. (1999). Orphanet: an online rare disease and orphan drug data base. Autosomal recessive limb-girdle muscular dystrophy type 2A. ORPHA:267

Autosomal recessive limb-girdle muscular dystrophy type 2A (LGMD2A) is a subtype of autosomal recessive limb girdle muscular dystrophy characterized by a variable age of onset of progressive, typically symmetrical and selective weakness and atrophy of proximal shoulder- and pelvic-girdle muscles (gluteus maximus, thigh adductors, and muscles of the posterior compartment of the limbs are most commonly affected) without cardiac or facial involvement. Clinical manifestations include exercise intolerance, a waddling gait, scapular wing ing and calf pseudo-hypertrophy. 